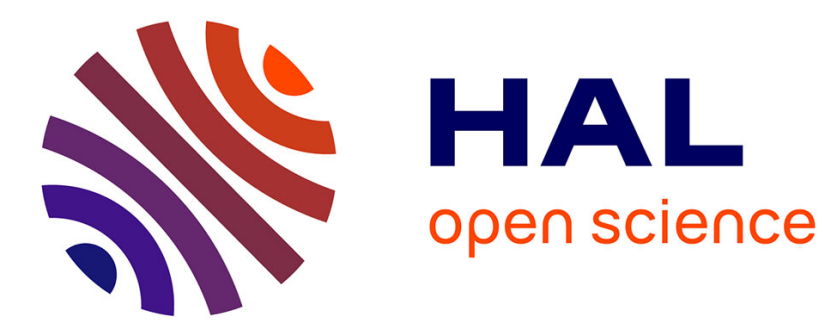

\title{
Thermal conductivity of meso-porous germanium
}

Mykola Isaiev, Sergii Tutashkonko, Valentin Jean, Konstantinos Termentzidis,

Tetyana Nychyporuk, Dmitriy Andrusenko, O. Marty, R. Burbelo, David

Lacroix, Vladimir Lysenko

\section{- To cite this version:}

Mykola Isaiev, Sergii Tutashkonko, Valentin Jean, Konstantinos Termentzidis, Tetyana Nychyporuk, et al.. Thermal conductivity of meso-porous germanium. Applied Physics Letters, 2014, 105 (3), 105 / 5p. 10.1063/1.4891196 . hal-01432202

\section{HAL Id: hal-01432202 \\ https://hal.univ-lorraine.fr/hal-01432202}

Submitted on 11 Jan 2017

HAL is a multi-disciplinary open access archive for the deposit and dissemination of scientific research documents, whether they are published or not. The documents may come from teaching and research institutions in France or abroad, or from public or private research centers.
L'archive ouverte pluridisciplinaire HAL, est destinée au dépôt et à la diffusion de documents scientifiques de niveau recherche, publiés ou non, émanant des établissements d'enseignement et de recherche français ou étrangers, des laboratoires publics ou privés. 


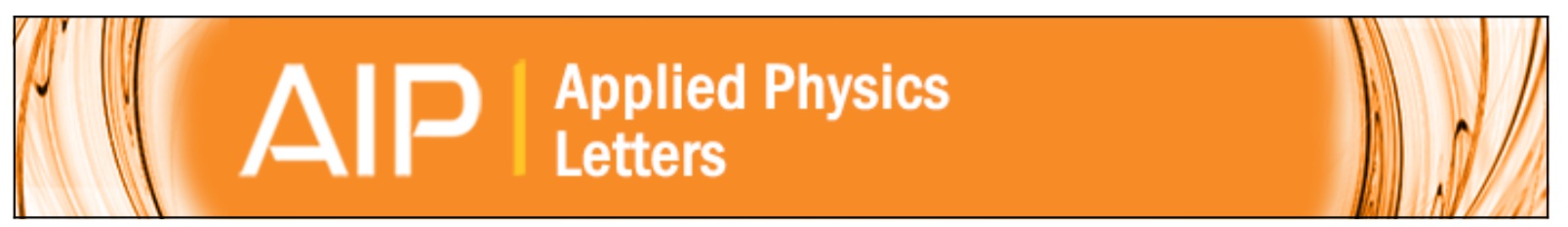

\section{Thermal conductivity of meso-porous germanium}

M. Isaiev, S. Tutashkonko, V. Jean, K. Termentzidis, T. Nychyporuk, D. Andrusenko, O. Marty, R. M. Burbelo,

D. Lacroix, and V. Lysenko

Citation: Applied Physics Letters 105, 031912 (2014); doi: 10.1063/1.4891196

View online: http://dx.doi.org/10.1063/1.4891196

View Table of Contents: http://scitation.aip.org/content/aip/journal/apl/105/3?ver=pdfcov

Published by the AIP Publishing

\section{AP $\mid \begin{aligned} & \text { Journal of } \\ & \text { Applied Physics }\end{aligned}$}

Journal of Applied Physics is pleased to announce André Anders as its new Editor-in-Chief 


\title{
Thermal conductivity of meso-porous germanium
}

\author{
M. Isaiev, ${ }^{1, a)}$ S. Tutashkonko, ${ }^{2,3}$ V. Jean, ${ }^{4} \mathrm{~K}$. Termentzidis, ${ }^{4}$ T. Nychyporuk, ${ }^{2}$ \\ D. Andrusenko, ${ }^{1}$ O. Marty, ${ }^{2}$ R. M. Burbelo, ${ }^{1}$ D. Lacroix ${ }^{4}$ and V. Lysenko ${ }^{2}$ \\ ${ }^{1}$ Faculty of Physics, Taras Shevchenko National University of Kyiv, 64/13, Volodymyrs' ka St., Kyiv 01601, \\ Ukraine \\ ${ }^{2}$ Université de Lyon; Institut des Nanotechnologies de Lyon, UMR-5270, site INSA de Lyon, Villeurbanne \\ F-69621, France \\ ${ }^{3}$ Institut Interdisciplinaire d'Innovation Technologique (3IT), Université de Sherbrooke, Québec JIK 2RI, \\ Canada \\ ${ }^{4}$ Université de Lorraine, LEMTA, CNRS-UMR7563, BP 70239, 54506 Vandoeuvre Cedex, France
}

(Received 22 June 2014; accepted 13 July 2014; published online 23 July 2014)

\begin{abstract}
Thermal conductivity value of sponge-like meso-porous germanium (meso-PGe) layers measured by means of photoacoustic technique is reported. The room temperature thermal conductivity value is found to be equal to $0.6 \mathrm{~W} /(\mathrm{m} \mathrm{K})$. The experimental results are in excellent agreement with molecular dynamic and Monte Carlo simulations. Both experiments and simulations show an important thermal conductivity reduction of the meso-PGe layers compared to the bulk Ge. The obtained results reveal meso-PGe as an interesting candidate for both thermoelectric and photovoltaic applications in which thermal transport is a really crucial issue. (c) 2014 AIP Publishing LLC.

[http://dx.doi.org/10.1063/1.4891196]
\end{abstract}

Numerous theoretical and experimental results obtained during the last $15 \mathrm{yr}$ pointed out extremely reduced heat transfer in low-dimensional structures in comparison with corresponding bulk materials. ${ }^{1-4}$ Depending on an aimed application, the thermal transport reduction can be either a serious drawback (functional deterioration of overheated components) or an attractive benefit (efficient thermal insulation for thermoelectric applications). ${ }^{5}$ Thus, understanding the fundamental mechanisms involved in the thermal transport phenomena occurring in low-dimensional materials is of the first importance, which will allow an optimal operation of various devices and systems.

Nanostructures of the IVth group such as silicon, germanium, silicon carbide, and carbon are of particular interest and are expected to continue playing an essential role in the future of nanosciences and nanotechnologies. For example, porous silicon (PSi) nanostructures made by electrochemical etching of silicon wafers has a thermal conductivity which is 2-3 orders of magnitude lower than that of bulk silicon substrates. ${ }^{6,7}$ This is mainly due to: (i) its strongly percolated porous network, (ii) phonon scattering on the nanocrystallite surface, as well as (iii) increased phonon-phonon scattering caused by lowering the dimension of the structures. ${ }^{8}$ Its low thermal conductivity combined with easy fabrication on silicon substrates make PSi an interesting material for thermal insulation in microelectromechanical systems and sensors. ${ }^{9,10}$

Cross-plane thermal conductivity of meso-porous $\mathrm{Ge}$ (meso-PGe) films has been recently experimentally measured by Raman scattering spectroscopy. ${ }^{11}$ This late experimental exploration is mainly due to the difficulty related to fabrication of sufficiently thick homogeneous meso-PGe layers with clearly defined morphologies and it was a big technological challenge for a long time. ${ }^{12}$ Only recently, this

\footnotetext{
${ }^{\text {a) }}$ Author to whom correspondence should be addressed. Electronic mail: isaev@univ.kiev.ua
}

barrier has been overcome ${ }^{13}$ and this breakthrough opens new possibilities for deep scientific studies of physicochemical properties and for design of various applications of the meso-PGe layers. ${ }^{14-16}$

In this Letter, thermal conductivity measurements performed by photoacoustic (PA) technique on sponge-like meso-PGe layers fabricated by electro-chemical etching are reported. Moreover, heat transport in the meso-PGe layers constituted by partially amorphous Ge nanocrystallites is theoretically simulated by molecular dynamic (MD) and Monte Carlo (MC) methods and an excellent agreement between the experimental and theoretical results is found.

Galvanostatic electrochemical etching was carried out on $100 \mu \mathrm{m}$ thick highly Ga doped p-type $(0.005-0.04 \Omega \mathrm{cm})$ Ge wafers with (100) orientation. Before the etching, the wafers were cleaned for 5 min in 3 washing steps: (1) deionized water, (2) acetone, (3) ethanol, and then were immediately dried under nitrogen flow. The cleaned Ge wafer was built in a homemade Teflon ${ }^{\circledR}$ cell with a back-side copper electrode and a $\mathrm{Pt} / \mathrm{Rh}$ loop wire as a counter electrode. Undiluted $\mathrm{HF}_{49 \%}$ acid was used as an electrolyte. Bipolar electrochemical etching technique described previously ${ }^{10}$ was applied to form thick $(\sim 2 \mu \mathrm{m})$ homogeneous spongelike meso-PGe layers of $50 \%$ porosity. Anodization current density $\left(1.8 \mathrm{~mA} / \mathrm{cm}^{2}\right)$ was applied in form of rectangular bipolar anodic and cathodic pulses with durations of 1 and $2 \mathrm{~s}$, respectively. The prepared porous samples were stored in air at room temperature.

A typical cross-section scanning electron microscope (SEM) view of the meso-PGe layer prepared under these experimental conditions is shown in Figure 1(a). Homogeneous and highly interconnected sponge-like porous network can be observed. The average pore diameter estimated from the SEM image is found to be in the range between 3 and $8 \mathrm{~nm}$. Interconnected Ge nanocrystals constituting the porous layer are shown on the transmission electron microscopy (TEM) 


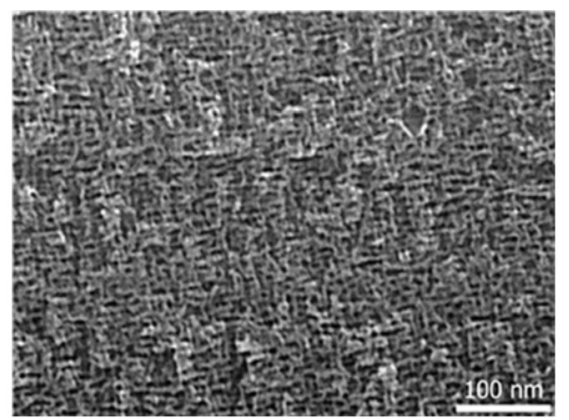

(a)

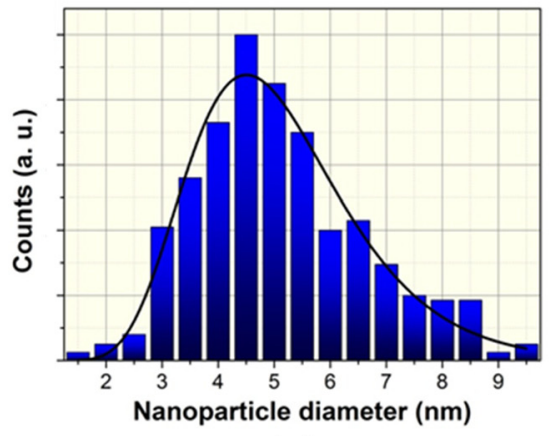

(c)

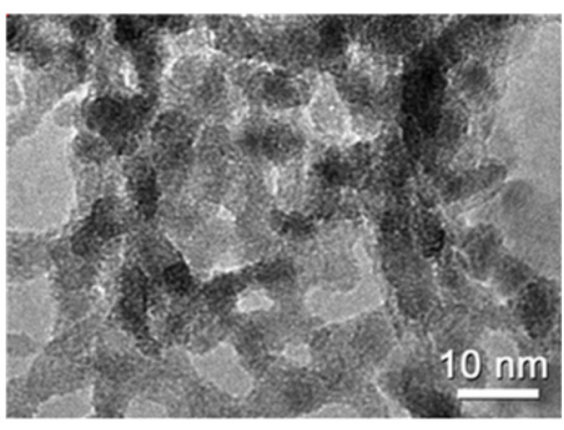

(b)

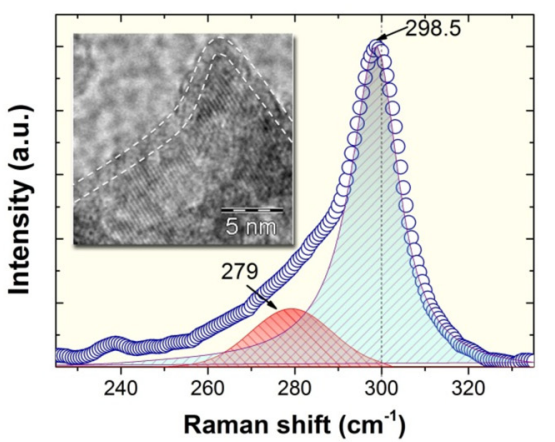

(d)
FIG. 1. (a) Cross-section SEM view of the meso-PGe layer, (b) TEM picture of the sponge-like porous network, (c) size distribution of the nanocrystals, (d) characteristic Raman spectrum of the meso-PGe layer. picture in Figure 1(b). Log-normal-like size distribution of the nanocrystals centered at $4.9 \mathrm{~nm}$ with standard deviation of $0.3 \mathrm{~nm}$ is presented in Figure 1(c).

In order to get further insight into the structural properties of the fabricated meso-PGe layers, micro-Raman scattering spectroscopy measurements were carried out. In our study, Raman spectra were recorded at room temperature on (001)-oriented cross-section plane of the meso-PGe layers with the use of an excitation wavelength of $514 \mathrm{~nm}$ and an excitation power of $0.5 \mathrm{~mW} / \mathrm{cm}^{2}$ applied through an objective $\times 100$. The obtained characteristic Raman spectrum (opened circles) of the meso-PGe layer is shown in Figure 1(d). As one can see, width, shape, and spectral position of the Raman peak strongly differ from well-known quite narrow symmetric and centered at $300 \mathrm{~cm}^{-1}$ peak of original monocrystalline Ge substrate. ${ }^{17}$ Indeed, the former is wider, red shifted, and asymmetrically broadened towards the lower frequency because of partial selection rule breakdown for the backscattered Stokes Raman signal recorded in these conditions. ${ }^{17-20}$ A phenomenological phonon-confinement model initially developed for nano- $\mathrm{Si}^{16}$ allows estimation of a mean diameter of the Ge nanocrystallites from the spectral position and the asymmetric shape of the Raman spectrum. The Raman profile calculated from the phonon-confinement model ${ }^{13}$ is presented as a hatched blue area in Figure 1(d). The mean crystallite diameter of $3.1 \mathrm{~nm}$ with standard deviation of $0.68 \mathrm{~nm}$ was found from the model to ensure the best fitting of the high energy tail and position of the peak maximum. However, in order to perfectly fit the whole spectrum, an intense band corresponding to amorphous $\mathrm{Ge}$ (a-Ge) which is centered near $279 \mathrm{~cm}^{-1}$ (hatched red area) has to be taken into account. This amorphous phase can correspond to the disordered $\sim 1 \mathrm{~nm}$ thick shell covering the Ge nanocrystallites which is quite well visible at high resolution TEM picture shown as insert in Figure 1(d). Taking in to account thickness of the amorphous shell and diameter of the crystalline core, a good agreement with the size distribution shown in Figure 1 (c) can be stated.

Simulations of thermal transport in the PGe layers were performed by means of MD and MC methods taking into account structural features described above. In the first case, a Non-Equilibrium Molecular Dynamics (NEMD) simulation method $^{21}$ was used and the PGe layer was modelled as a network of interconnected "crystalline core/amorphous shell" Ge nanoparticles (as shown in Figure 2) separated by voids with comparable sizes. According to the structural particularities of the PGe layers, dimensions of the crystalline core and thickness of the amorphous shell are considered to be $3 \mathrm{~nm}$ and $1 \mathrm{~nm}$, respectively. Details of the modeling of amorphous/crystalline interfaces can be found in a recent article. ${ }^{22}$ The modelled porous network was relaxed before the thermal conductivity simulations. The thermal conductivity value of

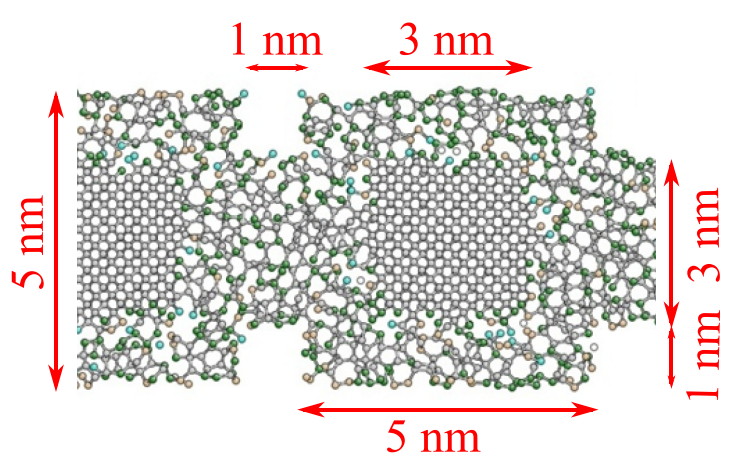

FIG. 2. The cross section of the modeled crystalline core/amorphous shell germanium nanoparticles with molecular dynamics is depicted. The characteristic lengths of the geometry are given. Grey atoms indicate fourcoordinated atoms, blue with one, yellow with two and green with three. 
the meso-PGe layers was found to be $0.6 \mathrm{~W} /(\mathrm{m} \mathrm{K})$. This value is about $45 \%$ of the value of completely amorphous porous Ge network and 7\% of the value of completely crystalline porous Ge layers. Such a huge reduction shows that the synergy between porosification and amorphization are the key parameters to obtain ultralow thermal conductivity.

The second simulation approach is based on solving of Boltzmann Transport Equation (BTE) with the use of a MC algorithm. ${ }^{23,24}$ Several spheres of the same size representing the pores are randomly distributed to model the meso-PGe nanostructure. The BTE is statistically solved under the relaxation time approximation. ${ }^{25}$ With the $\mathrm{MC}$ technique, phonons are treated as energy bundles which are randomly sampled according to distribution laws and selection rules (frequency, group velocity, and polarization). Phonons are allowed to move within the nanoporous network according to their sampled velocity and propagation direction. Phonons are assumed to be scattered at nanopore boundaries. Other scattering processes discussed below are also taken into account in the restoration of the equilibrium procedure. For relatively high porosities, direct MC simulation can be very long due to a big number of phonon scattering events occurring on the pore boundary. Thus, an Effective Monte Carlo (EMC) model has been developed in order to accelerate the calculation process. According to this model, the phonon scattering events are considered to be independent and a corresponding supplementary relaxation time $\left(\tau_{n p}^{-1}\right)$ is introduced. This new relaxation time is evaluated on the basis of a ray-tracing technique for which a large amount of phonons are tracked in a real porous structure during a single time step $\Delta \mathrm{t}^{22}$ The global relaxation time is given by the Matthiesen's rule ${ }^{26}$

$$
\begin{aligned}
\tau^{-1}(\varpi, T)= & \tau_{\mathrm{N}}^{-1}(\varpi, T)+\tau_{\mathrm{U}}^{-1}(\varpi, T)+\tau_{\mathrm{I}}^{-1}(\varpi, T) \\
& +\tau_{\mathrm{np}}^{-1}(\varpi, T),
\end{aligned}
$$

where $\tau_{\mathrm{X}}^{-1}(\varpi, T)$ are the relaxation times for a series of processes, and the index $x$ corresponds, respectively, to normal $(\mathrm{N})$, umklapp (U), impurities (I), and nanopores (np). The three first relaxation times are given by the Holland's model. ${ }^{26}$ As for the nanopore-phonon interactions characterized by $\tau_{n p}^{-1}$, one can define a corresponding mean free path (MFP) $\Lambda_{n p}=v_{g} \cdot \tau_{n p}^{-1}$, where $v_{g}$ is the phonon group velocity. Figure 3 shows $\Lambda_{\text {np }}$ dependence on porosity at room temperature for a $2 \mu \mathrm{m}$ thick meso-PGe layer constituted by spheres with $3 \mathrm{~nm}$ radius. Our simulations show that the $\Lambda_{\mathrm{np}}$ does not depend on polarization and frequency in contrast to the MFP related to 3 phonon processes and to the scattering on impurities.

The BTE is then solved to deduce thermal conductivity value of a porous Ge layer at $300 \mathrm{~K}$ (Figure 4). Black dots correspond to the EMC calculations for $50 \%$ porosity. The reported evolution of the thermal conductivity shows a linear dependence of thermal conductivity on MFP $\left(\Lambda_{\mathrm{np}}\right)$. Thus, for the pore diameters in the range between 4 and $8 \mathrm{~nm}$, we have plotted the interpolated values of the thermal conductivity considering a linear variation in this domain (blue triangles). We find a reduction of the bulk thermal conductivity of almost two decades, or in absolute values a thermal conductivity near $0.52 \mathrm{~W} /(\mathrm{m} \mathrm{K})$ for the pore diameter of $7 \mathrm{~nm}$ and porosity of

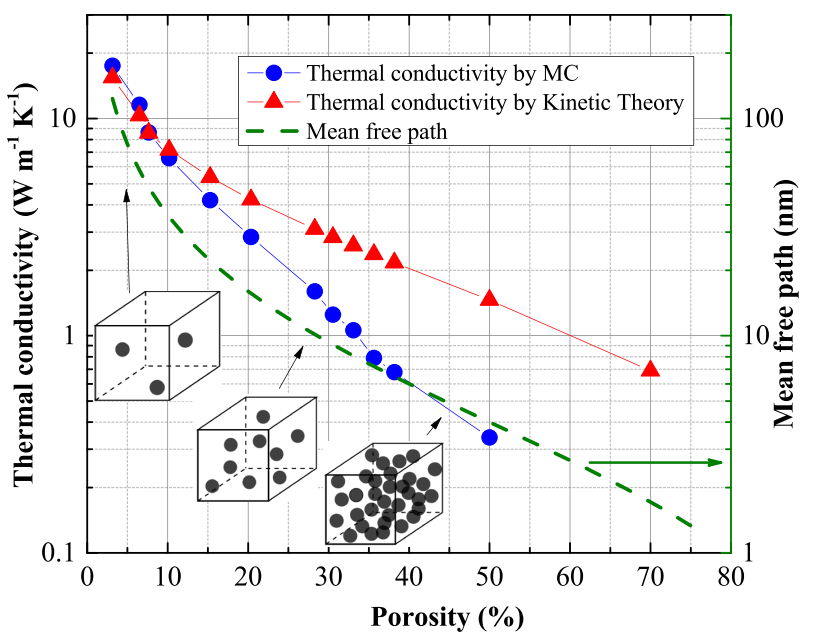

FIG. 3. Left axis: Thermal conductivity variations of a mesoporous germanium thin film with a uniform pore diameter $\mathrm{d}=6 \mathrm{~nm}$ as a function of the porosity; blue dots correspond to Monte Carlo simulations, red triangles correspond to the kinetic theory model. Right axis: Nanoporous phonon mean free path as a function of the porosity for a uniform pore diameter $d=6 \mathrm{~nm}$ (green dashed line).

$50 \%$. In addition, it shall be kept in mind that the calculations have been done for a uniform pore diameter distribution whereas the SEM pictures show a pore size dispersion. This fact can lead to a slight shift of the overall thermal conductivity of the meso-PGe thin films.

For the experimental evaluation of the meso-PGe thermal conductivity, PA gas-microphone technique already described by Isaiev et al. ${ }^{27}$ and shown in Figure 5(a) was applied. Two light emitting diodes (LEDs) with maximum spectral density wavelengths at $\lambda_{1}=470 \mathrm{~nm}$ and $\lambda_{2}=670 \mathrm{~nm}$ were chosen as sources for excitation of PA signals. Different absorption coefficients of the meso-PGe layer at these wavelengths $\left(\alpha_{\mathrm{PGe}}\left(\lambda_{1}\right)=2.7 \mu \mathrm{m}^{-1} \quad\right.$ and $\left.\quad \alpha_{\mathrm{PGe}}\left(\lambda_{2}\right)=0.48 \mu \mathrm{m}^{-1}\right) \quad$ were obtained from ellipsometry measurements and are taken into account in order to accurately set spatial distribution of the absorbed light intensities for the both wavelengths. ${ }^{28}$

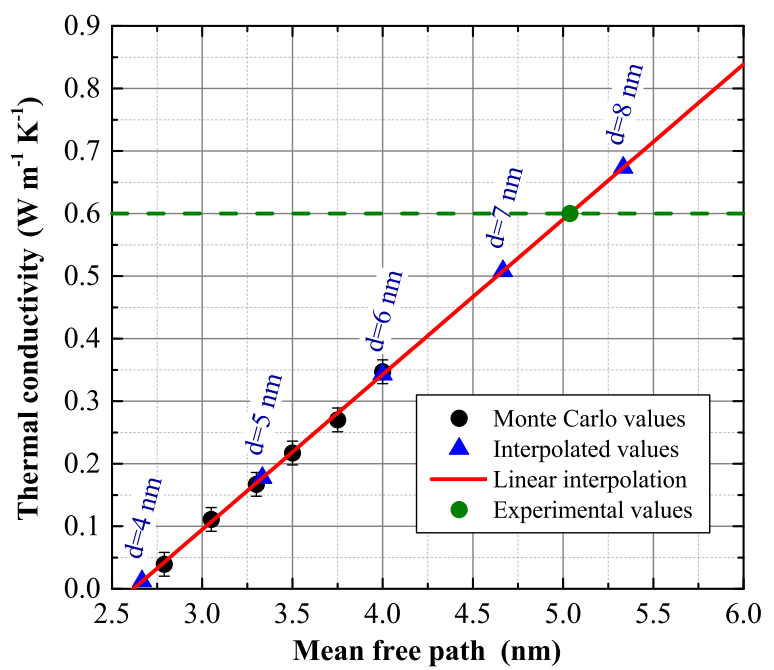

FIG. 4. Thermal conductivity variations of a mesoporous germanium thin film with a porosity of $50 \%$ as a function of the phonon mean free path due to porosity $\left(\Lambda_{\mathrm{np}}\right)$; black dots correspond to Monte Carlo simulations, blue triangles are interpolated values for equivalent diameters, green dot is the experimental results. 


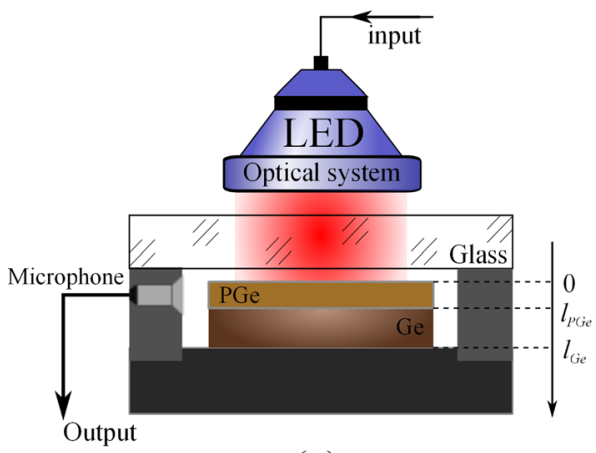

(a)

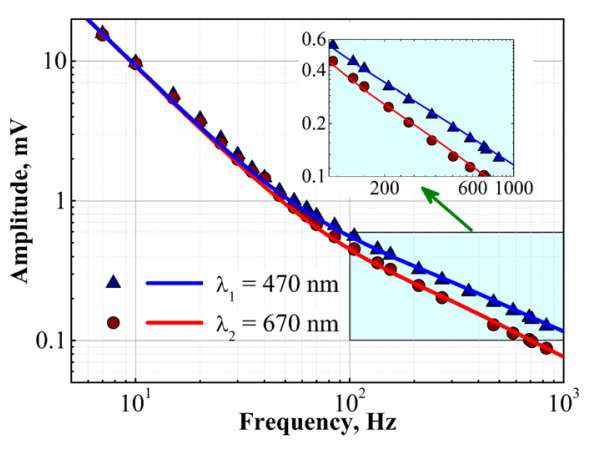

(b)
Experimentally detected dependences of the PA signal amplitude on modulation frequency for each LED are presented by symbols in Figure 5(b). The obtained experimental data were fitted with the use of Rosencwaig and Gersho model developed for thermal conductivity evaluation. In the frame of this model, the following multilayered system set in the PA cell was considered: gas (air), meso-PGe layer, monocrystalline Ge wafer, and a dielectric substrate. In order to calculate the spatial distribution of AC temperature component $(\theta)$ in this system, non-homogeneous heat-diffusion equation can be written in the following form:

$$
\frac{d}{d z}\left(K \frac{d \theta}{d z}\right)-i 2 \pi \nu c \rho \theta=f(z)
$$

where $K, c$, and $\rho$ are the spatial distribution of thermal conductivity, specific heat capacity, and density in the considered multilayer system, respectively; $f(z)$ is the function describing the spatial distribution of the absorbed light intensity

$$
f(z)=I_{0}(1-R) \alpha \exp \left(-\int_{0}^{z} \alpha\left(z^{\prime}\right) d z^{\prime}\right) .
$$

In the case of excitation with $\lambda_{1}$, according to the fact that there is almost a total absorption of the exciting light inside the porous Ge layer, the expression of $f(z)$ can be reduced to

$$
f(z)=I_{0}(1-R) \alpha_{P G e} \exp \left(-\alpha_{P G e} z\right) .
$$

Oppositely, in the case of an excitation at the wavelength $\lambda_{2}$, the light source intensity can reach the Ge wafer, and thus Eq. (3) becomes

$$
f(z)=I_{0}(1-R) \times\left\{\begin{array}{l}
\alpha_{P G e} \exp \left(-\alpha_{P G e} z\right) \\
\alpha_{G e} \exp \left(\left(\alpha_{G e}-\alpha_{P G e}\right) l_{P G e}\right) \exp \left(-\alpha_{G e} z\right),
\end{array}\right.
$$

where $l_{P G e}$ thickness of PGe layer.

Equation (2) can be numerically solved to calculate $\theta(z)$ by finite difference method taking into account the boundary conditions related to the absence of thermal perturbation far from the studied layers $(z= \pm \infty)$. According to Rosencwaig and Gersho model, ${ }^{29}$ the temperature distribution in the gas $(\theta(z<0))$ defines pressures oscillation in the PA cell $(p(\nu))$ forming the detected PA signal
FIG. 5. (a) Sketch-view of the used photoacoustic cell (b) Experimental amplitude frequency dependences (symbols) for the meso-PGe layers at different excitation wavelengths. The best theoretical fitting of the experimental curves are presented by continuous lines.

$$
p(\nu) \sim \int_{0}^{-\infty} \theta(z, \nu) d z
$$

The obtained experimental amplitude-frequency characteristics were fitted by Eq. (6) as it is shown in Figure 5(b) by solid lines for the both excitation wavelengths with thermal conductivity of the meso-PGe layers as a fitting parameter. The best fitting was obtained for $K=0.6 \mathrm{~W} /(\mathrm{m} \mathrm{K})$, which is in excellent agreement with the values estimated from numerical simulation.

In conclusions, the present study provides a comprehensive evaluation of the morphology dependent thermal conductivity of thin meso-PGe films. First of all, electronic microscopy and Raman spectroscopy were used to evaluate size and pore distribution within the meso-PGe samples. From these studies, strongly interconnected Ge nanoparticles with mean diameters near $5 \mathrm{~nm}$ covered by a thin amorphous layer have been found to constitute the meso-PGe layers. On the basis of these observations, two numerical techniques were used to appraise the meso-PGe thermal conductivity: molecular dynamics and Monte Carlo solution of the Boltzmann transport equation. The results obtained by the both theoretical approaches are found to be in good agreement with experimental measurements based on photoacoustic technique. In particular, at room temperature, meso-PGe thermal conductivity is found to be two orders of magnitudes lower $(0.6 \mathrm{~W} /(\mathrm{m} \mathrm{K}))$ than that of bulk Ge substrates $(58 \mathrm{~W} /(\mathrm{m} \mathrm{K}))$. This result correlates quite well with similar observations done on nano-porous Si (Ref. 30) and nanoporous SiGe (Ref. 31) structures.

${ }^{1}$ D. G. Cahill, W. K. Ford, K. E. Goodson, G. D. Mahan, A. Majumdar, H. J. Maris, R. Merlin, and S. R. Phillpot, J. Appl. Phys. 93, 793-818 (2003).

${ }^{2}$ A. Chernatynskiy, D. R. Clarke, and S. R. Phillpot, in Handbook of Nanoscience, Engineering, and Technology, edited by W. A. Goddard III, D. Brenner, S. E. Lyshevski, and G. J. Iafrate (CRC Press, Boca Raton, London, New York, Washington, D.C., Third., 2012), pp. 545-572.

${ }^{3}$ K. Termentzidis, O. Pokropyvnyy, M. Woda, S. Xiong, Y. Chumakov, P. Cortona, and S. Volz, J. Appl. Phys. 113, 013506 (2013).

${ }^{4}$ P. Chantrenne and K. Termentzidis, Phys. Status Solidi A 209, 2492-2498 (2012).

${ }^{5}$ D. G. Cahill, P. V. Braun, G. Chen, D. R. Clarke, S. Fan, K. E. Goodson, P. Keblinski, W. P. King, G. D. Mahan, A. Majumdar, H. J. Maris, S. R. Phillpot, E. Pop, and L. Shi, Appl. Phys. Rev. 1(1-45), 011305 (2014).

${ }^{6} \mathrm{G}$. Benedetto, L. Boarino, and R. Spagnolo, Appl. Phys. A 64, 155-159 (1997).

${ }^{7}$ G. Gesele, J. Linsmeier, V. Drach, J. Fricke, and R. Arens-Fischer, J. Phys. D: Appl. Phys. 30, 2911-2916 (1997).

${ }^{8}$ A. Minnich and G. Chen, Appl. Phys. Lett. 91, 073105 (2007). 
${ }^{9}$ P. J. Newby, B. Canut, J.-M. Bluet, S. Gomès, M. Isaiev, R. Burbelo, K. Termentzidis, P. Chantrenne, L. G. Fréchette, and V. Lysenko, J. Appl. Phys. 114, 014903 (2013).

${ }^{10}$ P. Roussel, V. Lysenko, B. Remaki, G. Delhomme, A. Dittmar, and D. Barbier, Sens. Actuators, A 74, 100-103 (1999).

${ }^{11}$ B. Stoib, S. Filser, N. Petermann, H. Wiggers, M. Stutzmann, and M. S. Brandt, Appl. Phys. Lett. 104(1-4), 161907 (2014).

${ }^{12}$ C. Fang, H. Föll, and J. Carstensen, J. Electroanal. Chem. 589, 259-288 (2006).

${ }^{13}$ S. Tutashkonko, A. Boucherif, T. Nychyporuk, A. Kaminski-Cachopo, R. Arès, M. Lemiti, and V. Aimez, Electrochim. Acta 88, 256-262 (2013).

${ }^{14}$ S. Tutashkonko, T. Nychyporuk, V. Lysenko, and M. Lemiti, J. Appl. Phys. 113, 023517 (2013).

${ }^{15}$ A. Boucherif, G. Beaudin, V. Aimez, and R. Arès, Appl. Phys. Lett. 102, 011915 (2013).

${ }^{16}$ E. Garralaga Rojas, B. Terheiden, H. Plagwitz, J. Hensen, C. Baur, G. F. X. Strobl, and R. Brendel, Electrochem. Commun. 12, 231-233 (2010).

${ }^{17}$ K. Roodenko, I. A. Goldthorpe, P. C. McIntyre, and Y. J. Chabal, Phys. Rev. B 82, 115210 (2010).

${ }^{18} \mathrm{P}$. M. Fauchet, in Light Scattering in Semiconductor Structures and Superlattices, edited by D. J. Lockwood and J. F. Young (Springer Science+ Business Media, LLC, New York and London, 1991), pp. 229-245.
${ }^{19}$ S.-F. Ren and W. Cheng, Phys. Rev. B 66, 205328 (2002).

${ }^{20}$ G. Kartopu, A. V. Sapelkin, V. A. Karavanskii, U. Serincan, and R. Turan, J. Appl. Phys. 103, 113518 (2008).

${ }^{21}$ K. Termentzidis, P. Chantrenne, and P. Keblinski, Phys. Rev. B 79, 214307 (2009).

${ }^{22}$ A. France-Lanord, E. Blandre, T. Albaret, S. Merabia, D. Lacroix, and K. Termentzidis, J. Phys.: Condens. Matter 26, 055011 (2014).

${ }^{23}$ D. Lacroix, K. Joulain, and D. Lemonnier, Phys. Rev. B 72, 064305 (2005).

${ }^{24}$ V. Jean, S. Fumeron, K. Termentzidis, S. Tutashkonko, and D. Lacroix, J. Appl. Phys. 115, 024304 (2014).

${ }^{25}$ P. Carruthers, Rev. Modern Phys. 33, 92-138 (1961).

${ }^{26}$ M. G. Holland, Phys. Rev. 132, 2461-2471 (1963).

${ }^{27}$ M. Isaiev, P. J. Newby, B. Canut, A. Tytarenko, P. Lishchuk, D. Andrusenko, S. Gomès, J.-M. Bluet, L. G. Fréchette, V. Lysenko, and R. Burbelo, Mater. Lett. 128, 71-74 (2014).

${ }^{28}$ A. I. Tytarenko, D. A. Andrusenko, A. G. Kuzmich, I. V. Gavril, V. A. Skryshevskii, M. V. Isaiev, and R. M. Burbelo, Tech. Phys. Lett. 40, 188-191 (2014).

${ }^{29}$ A. Rosencwaig and A. Gersho, J. Appl. Phys. 47, 64-69 (1976).

${ }^{30}$ J.-H. Lee, G. A. Galli, and J. C. Grossman, Nano Lett. 8, 3750-3754 (2008).

${ }^{31}$ Y. He, D. Donadio, and G. Galli, Nano Lett. 11, 3608-3611 (2011). 